\title{
COVID-19 Lockdown and its Impact on Mental Health in Various Population Groups in Greece: A Cross-Sectional Study
}

\author{
Konstantinos Argyropoulos a, Konstantinos Krikonis b, Eleni Jelastopulu a iD \\ a Department of Public Health, School of Medicine, University of Patras, Greece. \\ b Statistics and Research Design Company, DatAnalysis, Ioannina, Greece.
}

\begin{abstract}
Introduction: COVID-19 pandemic and lockdown has brought a serious impact on physical and mental health. Objective: The purpose of the present study was to estimate the impact of the first lockdown in Greece, on both quality of life and anxiety levels in different occupational groups. Methods: A cross-sectional on- line survey was conducted from 20th of April to 4th of May 2020. A 24-item anonymous questionnaire was administered to collect basic demographic and socioeconomic data. The 5-item WHO Well-Being Index (WHO-5, 0-100\%, cut-off 52\%) and the Generalized Anxiety Disorder Assessment (GAD-7) tools were used to assess well-being and anxiety, respectively. Statistical analysis was performed with SPSS for Windows v.24.0 Statistical Package. Results: A total of 575 participated in the study, $62.8 \%$ females, $48.5 \%$ aged between 40 to 59 years. $32.5 \%$ were employed in education sector, $32.5 \%$ in health sector and $20.3 \%$ as season workers in tourism sector. Males showed slightly higher levels of wellbeing (52.1 vs. 47.3, p=0.023) and lower levels of anxiety (7.1 vs. 8.2, $\mathrm{p}=0.023$ ) compared to females. Factors associated with higher wellbeing and lower anxiety were higher education and income level, optimism, taking less protection measures, and being seasonal worker. Furthermore, participants with comorbidities and symptoms like headache, musculoskeletal pain, as well as feeling depressed or stressed revealed lower wellbeing and higher anxiety scores.

Discussion: Our study revealed an overall poor wellbeing and mild to moderate levels of anxiety during the lockdown. Actions should be taken to address and to prevent its serious impact on mental health.
\end{abstract}

KEYWORDS: COVID-19; Lockdown; WHO-5; GAD-7

Correspondence: Eleni Jelastopulu, Professor of Public Health, Department of Public Health, School of Medicine, University of Patras, 26500 Rio, Greece. Email: jelasto@upatras.gr

Copyright $\odot 2021$ Argyropoulos $\mathbf{K}$ et al. This is an open access article distributed under the Creative Commons Attribution

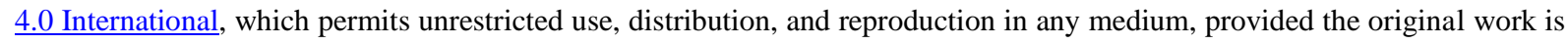
properly cited.

\section{INTRODUCTION}

COVID-19 may be a physical illness but it has also hit mental health hard. COVID-19 pandemic and the subsequent lockdown has brought about a sense of fear and anxiety around the globe, and a rise in people reporting severe mental health disorders (1). The WHO has emphasized the extremely high burden on workers, and called for action to address the immediate needs and take measures to prevent a serious impact on physical and mental health of all employees (2).

Throughout the world, isolation and social distancing strategies has been imposed as the most essential prevention measures against COVID- 19 infection. On these grounds, since January, 2020, various countries started implementing regional and national lockdowns. Some of the principal measures taken during lockdown has been closure of schools, educational institutes and activity areas as well as remote work and part-time job $(1,3)$

These inexorable circumstances which are beyond normal experience, has led to short term as well as long term psychosocial and mental health implications, such as stress, anxiety and a feeling of helplessness (4). The quality and magnitude of impact on the wellbeing is determined by many vulnerability factors like preexisting mental health condition, being economically underprivileged, the educational status, or being quarantined due to infection or fear of infection (1).

A team analyzed data from the Understanding Society COVID-19 Study (5), looking at the relation between changes in employment status and work hours, and the 
likelihood of mental health problems. Workers who were on leave or had to switch from full- to part-time during April and May 2020, as well as people who lost their job and thus their livelihoods, were at higher risk of poor mental health and quality of life.

The impact of coronavirus having on the mental health of the workers depends on a pre-existing mental health issue that is worsening due to the lockdown, the educational and economic level. A reduction or loss of salary and job security could also play a role. Not knowing if they will stay in their jobs and feeling unappreciated is a major cause for poor mental health among workers. Loss of earnings explains only a small part of the large mental health deficit associated with lockdown. Additional aspects of employment, such as social connection, structure or common goals, are just as important for wellbeing as the work itself $(5,6)$.

\section{MATERIALS AND METHODS}

More than 500 respondents from all territories of Greece participated in this cross-sectional study, completing an online questionnaire from 20th of April to 4th of May 2020, via several social media platforms.

The 24-item anonymous questionnaire was administered to collect basic socio-demographic characteristics, such as age, gender, place of living, educational, occupational and economic status, having children, comorbidity, as well as data regarding changes in their occupational status during the lockdown. The participants were also asked about their practices and perceptions towards COVID-19 pandemic. The last section of the questionnaire comprised two instruments measuring their quality of life and anxiety levels, the WHO-5 and the GAD-7 respectively.

The 5-item World Health Organization Well-Being Index (WHO-5) is a short rating scale measuring subjective well-being (7). The WHO-5 items are: 1 . I have felt cheerful and in good spirits, 2. I have felt calm and relaxed, 3. I have felt active and vigorous, 4. I woke up feeling fresh and rested and 5. My daily life has been filled with things that interest me. The respondent is asked to rate how well each of the 5 statements applies to him or her when considering the last 14 days. Each of the 5 items is scored from 5 (all of the time) to 0 (none of the time). The raw score therefore theoretically ranges from 0 (absence of well-being) to 25 (maximal well-being), with threshold score of 13. To obtain a percentage score ranging from 0 to 100 , the raw score is multiplied by 4 . A percentage score of 0 represents worst possible, whereas a score of 100 represents best possible quality of life with cut-off point $52 \%$.

The Generalized Anxiety Disorder Assessment (GAD-7) is a seven-item instrument that is used to measure or assess the severity of generalized anxiety disorder (GAD). The GAD-7 has been validated for primary care patients, general population, and adolescents with GAD (8).

The participants are asked to answer how often over the past two weeks have been bothered by the following problems: 1. Feeling nervous, anxious, or on edge; 2 . Not being able to stop or control worrying; 3 . Worrying too much about different things; 4. Trouble relaxing; 5. Being so restless that it's hard to sit still; 6 . Becoming easily annoyed or irritable; and 7. Feeling afraid as if something awful might happen. Each item asks the individual to rate the severity of his or her symptoms and is scored from 0 (not at all) to 3 (nearly every day). Scores of 5, 10, and 15 are taken as the cut-off points for mild, moderate and severe anxiety, respectively. Using the threshold score of 10 , the GAD-7 has a sensitivity of $89 \%$ and a specificity of $82 \%$ for GAD.

Statistical analysis was performed with SPSS for Windows v.24.0 Statistical Package. A chi square test was used to test the difference between categorical variables. $\mathrm{P}<0.05$ was considered as statistically significant. Fitting to a normal distribution, was assessed for every variable, with the Kolmogorov-Smirnov test, and it was not rejected in any case, ensuring the adequacy of parametric tests.

Variables showing at univariate analysis a statistical significant association with wellbeing and anxiety (wellbeing based on WHO-5 and anxiety levels according to GAD-7 questionnaire) were introduced in a multivariate model in order to evaluate the association for a number of potential confounders and effect modifiers: age (in years); gender; education (years of school); financial level (individual income in Euro per month); marital status (married, unmarried, widower, divorced); having children (yes/no); the number of diseases based on medical history (hypertension, musculoskeletal disorders, anxiety, depression diagnosed by a physician, hyperlipidemia, respiratory problems and Parkinson's disease) (yes/no), optimism regarding the next day after lockdown and personal hygiene measures.

In the Introduction page of the online questionnaire, we provided all the necessary information regarding the procedure, the scope, and the time to complete the survey. The participation was voluntarily, and the anonymity of the respondents was retained. The names as well as the e-mails of the authors were provided to the participants. Data was collected and protected in an encrypted hard drive. A digital consent of participation was derived before initiating the survey from each participant. The study was conducted in accordance with the Declaration of Helsinki Ethical Principles and Good Clinical Practices.

\section{RESULTS}

A total of 575 participants completed the online questionnaire, $62.8 \%$ were females, and $48.5 \%$ were between 40 to 59 years old. Table 1 presents the sociodemographic characteristics of the study population.

Employed in the education sector were $32.5 \%$, in health sector $32.5 \%$ and $20.3 \%$ declared being season workers in tourism sector. Males showed slightly but significant higher levels of wellbeing (52.1 vs. $47.3, \mathrm{p}=0.023$ ) and lower levels of anxiety ( 7.1 vs. $8.2, p=0.023$ ) compared to females (Table 2).

We observed statistically significant differences in the mean scores between the different professions. Beneath 
of the unemployed, who showed the lowest score in wellbeing (42.3\%) and the highest in anxiety (9.9\%), the teachers are also revealing low scores in WHO-5 (47.2\%) and high scores in GAD-7 (8.0), whereas in seasonal workers we observe the opposite, highest scores in wellbeing (55.1\%) and lowest scores in anxiety (6.2). (Table 3).

Table 1: Demographic Characteristics of the Study Population

\begin{tabular}{ll}
\hline Demographic Characteristics & N or \% \\
\hline Total recorded participants & 575 \\
\hline Male (\%)/female (\%) & $37.2 / 62.8$ \\
\hline Mean age in years $\mathbf{S D}$ & $45 \pm 8.1$ \\
\hline $\begin{array}{l}\text { Nationality } \\
\text { Hellenic/other (in \%) }\end{array}$ & $98.8 / 1.2$ \\
\hline $\begin{array}{l}\text { Educational level } \\
\text { Low (1-6years)/ Medium (7-12 years) /High (>12 years) (in\%) }\end{array}$ & $0.0 / 12.7 / 87.3$ \\
\hline Financial level & $16.3 / 32.9 / 34.3 / 16.5$ \\
$<500$ E/501-1000 E/1001-2000 E/>2001E (in \%) & \\
\hline $\begin{array}{l}\text { Marital status } \\
\text { Married/ Not married/ Divorced/ Widowed (in \%) }\end{array}$ & $72.0 / 3.3 / 3.3 / 21.3$ \\
\hline $\begin{array}{l}\text { Children } \\
\text { Yes/No (in \%) }\end{array}$ & $96.2 / 43.8$ \\
\hline $\begin{array}{l}\text { Place of Living } \\
\text { Urban/ Rural (in \%) }\end{array}$ & $78.4 / 21.6$ \\
\hline $\begin{array}{l}\text { Occupation } \\
\text { Teacher/ Health professional/ Season worker/ Unemployed (in \%) }\end{array}$ & $32.5 / 32.5 / 20.3 / 14.6$ \\
\hline $\begin{array}{l}\text { Lockdown impact on work } \\
\text { Fired/Suspension/Remote/Don't Know/ Not affected (in \%) }\end{array}$ & $2.4 / 14.3 / 22.4 / 14.3 / 46.6$ \\
\hline $\begin{array}{l}\text { Optimism } \\
\text { Not at all/ Little/ More or less/Enough/ Very much (in \%) }\end{array}$ & $15.5 / 17.4 / 25.7 / 31.3 / 10.1$ \\
\hline $\begin{array}{l}\text { Personal Hygiene Measures } \\
\text { Not at all/ Little/ More or less/Enough/ Very much (in \%) }\end{array}$ \\
\hline
\end{tabular}

Table 2: Correlations Between Gender and WHO-5 (as Percentage Score) \& GAD-7

\begin{tabular}{|c|c|c|c|c|c|c|c|}
\hline Gender & & $\mathbf{N}$ & Mean & SD & $\mathbf{t}$ & df & Sig. \\
\hline \multirow[t]{2}{*}{ WHO-5 Total Score } & Male & 214 & 52.1 & 24.6 & 2.272 & 573 & 0.023 \\
\hline & Female & 361 & 47.3 & 24.6 & & & \\
\hline \multirow{2}{*}{$\begin{array}{l}\text { Generalized Anxiety } \\
\text { Disorder (GAD-7) }\end{array}$} & Male & 214 & 7.1 & 5.3 & -2.273 & 573 & 0.023 \\
\hline & Female & 361 & 8.2 & 5.4 & & & \\
\hline
\end{tabular}

Table 3: Occupation in Association with WHO-5 (as Percentage Score) \& GAD-7

\begin{tabular}{|c|c|c|c|c|c|c|}
\hline Occupation & & $\mathrm{N}$ & Mean & SD & $\mathrm{F}$ & Sig. \\
\hline \multirow[t]{5}{*}{ WHO-5 Total Score } & Teacher & 187 & 47.2 & 22.7 & \multirow[t]{5}{*}{5.121} & \multirow[t]{5}{*}{0.002} \\
\hline & Health professional & 187 & 50.4 & 25.0 & & \\
\hline & Seasonal worker & 117 & 55.1 & 25.0 & & \\
\hline & Unemployed & 84 & 42.3 & 25.7 & & \\
\hline & Total & 575 & 49.1 & 24.7 & & \\
\hline \multirow{5}{*}{$\begin{array}{l}\text { Generalized Anxiety } \\
\text { Disorder (GAD-7) }\end{array}$} & Teacher & 187 & 8.0 & 5.5 & \multirow[t]{5}{*}{7.890} & \multirow[t]{5}{*}{0.000} \\
\hline & Health professional & 187 & 7.6 & 5.2 & & \\
\hline & Seasonal worker & 117 & 6.2 & 4.6 & & \\
\hline & Unemployed & 84 & 9.9 & 5.9 & & \\
\hline & Total & 575 & 7.8 & 5.4 & & \\
\hline
\end{tabular}

Factors identified to be associated with higher wellbeing and lower anxiety were higher education and income level, optimism, taking less protection measures, and being seasonal worker (Table 4).
Furthermore, participants with comorbidities and symptoms like headache, hypercholesterolemia, musculoskeletal pain, as well as feeling depressed or stressed revealed lower wellbeing and higher anxiety scores (Table 5; Table 6). 
Table 4: Educational and Financial level, Optimism and Personal hygiene measures in association with WHO-5 \& GAD-7

\begin{tabular}{llllll}
\hline & & Educational Level & Financial level & Optimism & $\begin{array}{l}\text { Personal } \\
\text { Hygiene } \\
\text { Measures }\end{array}$ \\
\hline WHO-5 Total & Correlation Coefficient & $.119^{* *}$ & $.128^{* *}$ & $.325^{* *}$ & $-.289^{* * *}$ \\
Score & Sig. (2-tailed) & 0.004 & 0.002 & 0.000 & 0.000 \\
& $\mathrm{~N}$ & 575 & 575 & 575 & 575 \\
\hline Generalized & Correlation Coefficient & $-.111^{* *}$ & $-.136^{* *}$ & $-.261^{* *}$ & $.412^{* *}$ \\
Anxiety Disorder & Sig. (2-tailed) & 0.007 & 0.001 & 0.000 & 0.000 \\
(GAD-7) & $\mathrm{N}$ & 575 & 575 & 575 & 575 \\
\hline
\end{tabular}

Table 5: Correlations between Com-Morbidities and WHO-5 \& GAD-7

\begin{tabular}{llllll}
\hline Comorbidity & & Headache & $\begin{array}{l}\text { Musculoskeletal } \\
\text { pain }\end{array}$ & Depression & Anxiety \\
\hline \multirow{2}{*}{ WHO-5 Total Score } & Correlation Coefficient & $-.210^{* *}$ & $-.161^{* *}$ & $-.427^{* *}$ & $-.446^{* *}$ \\
& Sig. (2-tailed) & 0.000 & 0.000 & 0.000 & 0.000 \\
& $\mathrm{~N}$ & 575 & 575 & 575 & 575 \\
\hline \multirow{2}{*}{ Generalized Anxiety } & Correlation Coefficient & $.299^{* *}$ & $.170^{* *}$ & $.538^{* *}$ & $.614^{* *}$ \\
Disorder (GAD-7) & Sig. (2-tailed) & 0.000 & 0.000 & 0.000 & 0.000 \\
& $\mathrm{~N}$ & 575 & 575 & 575 & 575 \\
\hline
\end{tabular}

Table 6: Hypercholesterolemia in Association with WHO-5 (as Percentage Score) \& GAD-7

\begin{tabular}{|c|c|c|c|c|c|c|c|}
\hline Hypercholesterolemia & & $\mathrm{N}$ & Mean & $\begin{array}{l}\text { Std. } \\
\text { Deviation }\end{array}$ & $\mathrm{t}$ & df & Sig. (2-tailed) \\
\hline \multirow{2}{*}{ WHO-5 Total Score } & No & 447 & 53.0 & 24.0 & \multirow{2}{*}{7.382} & \multirow{2}{*}{573} & \multirow[t]{2}{*}{0.000} \\
\hline & YES & 128 & 35.6 & 22.2 & & & \\
\hline \multirow{2}{*}{$\begin{array}{l}\text { Generalized Anxiety } \\
\text { Disorder (GAD-7) }\end{array}$} & No & 447 & 7.5 & 5.3 & \multirow{2}{*}{-2.767} & \multirow{2}{*}{573} & \multirow[t]{2}{*}{0.006} \\
\hline & YES & 128 & 9.0 & 5.6 & & & \\
\hline
\end{tabular}

\section{DISCUSSION}

The present study investigated the psychological impact of COVID-19 first lockdown measures on both anxiety levels and quality of life on different population groups. The sample of the study consisted mainly of employees and specifically examined the effect of COVID-19 quarantine in health care professionals, teachers, and seasonal employees. Mental disorders and stress are known to significantly reduce the quality of life of employees and at the same time significantly affect their professional performance (9).

Employees in health and education sector, as well as seasonal workers in tourism are front-line workers and it is more likely to be exposed and to encounter with patients suffering from COVID-19. Nurses and physicians come into daily contact with COVID-19 patients and they experience intense stress which is likely to affect the quality of care and services they provide, by making wrong decisions $(10,11)$.

During the first lockdown of COVID-19 pandemic, several researchers highlighted the need for interventions to support and safeguard the mental health of people affected by changes to their workplace $(11,12,13)$, with particular emphasis on health professionals and educators $(14,15)$.

Our study revealed the psychological effects of COVID19 lockdown measures on teachers, health professionals and seasonal workers who addressed dramatic changes in their working conditions either due to direct expose to the virus or losing their job, working remotely or seeing serious reduction in their salary $(6,16,17)$. According to our results, women reported lower quality of life and higher anxiety in comparison to men. In contrary to seasonal workers, employees in the educational sector presented with higher rates of anxiety, following by health professionals. Moreover, seasonal workers' mental health has been least affected, which may be explained by the study period in spring just before the opening of the touristic season in Greece. Changes in employment status has equally negatively affected the mental health and anxiety level of employees, with results and to their quality of life. Health professionals has faced an unprecedented situation, lacking the knowledge or the way which they should work to treat the COVID-19 symptoms, resulting in feeling mentally depressed and unable to provide adequate therapy $(18,19)$.

Moreover, working hours of health professionals has been significantly increased with detrimental impact on their quality of life, and the need to protect the mental and physical health of workers and specially to reduce their stress to become priority $(20,21)$.

The monthly income determines the quality of life and the levels of anxiety for most employees. According to O'Neill \& Davis (22) seasonal workers in tourism has already experienced higher working stress compared to the rest of the employees during the last years $(23,24)$. The spread of COVID- 19 pandemic has further deteriorated their mental health with the stress and insecurity to show increased rates directly affecting their quality of life. Seasonal workers have experienced high rates of stress and other related disorders because of their dismissal or their reduced income (25). Furloughing workers, as well as reducing worker hours, has helped to stem the tide of mental health problems expected to result from the coronavirus crisis. Using the latest data covering May 2020, a study found for those who lost their jobs and 
salary during the coronavirus crisis some $58 \%$ returned scores suggesting they were in the "at risk" category for mental health problems. Authors suggest that government must encourage employers to "cut hours not people" as furlough schemes wrap up, or face significantly worse levels of mental health across the population as unemployment soars. Holding on to some paid work is vital to wellbeing during the pandemic, both short working hours and furlough job retention schemes may helped protect against the deterioration of mental health. This study found that even a small number of working hours (between 1 and $8 \mathrm{~h}$ a week) generates significant mental health and well-being benefits (5).

On the other hand, workers attitude toward COVID-19 pandemic depend on their stress levels and their overall mental health. In a recent study, optimism about returning to the previous rhythms of life can reduce the stress of employees and allow them to enjoy a better quality of life, while on the other hand the observance of hygiene measures is a factor that stresses workers the most, resulting on the onset of mental disorders and poor quality of life. The experience of positive emotions such as optimism enhances the mental resilience of nurses and helps them cope with the stress (26). Safety in the workplace and compliance with the required measures and hygiene rules is a factor that affects the mental health of employees and burdens them with additional stress, while employees who feel insecure due to noncompliance with the prescribed hygiene rules are more likely to express lower quality of life $(24,26)$.

Furthermore, teachers during the pandemic and lockdown measures had to work harder and to learn to use new technologies that they were unaware until then, to facilitate the distance learning process. Changes in the way they work, and the challenge of virtual classroom management have caused additional stress for teachers (27,28).

The presence of health problems is another factor that contributes to the intensity of mental problems such as anxiety disorder and poor quality of life of all employees. Exposure to a stressful environment may deteriorate chronic health problems from which an employee may suffer, such as hypercholesterolemia, chronic stress and obesity while at the same time, an employee's illnesses have a negative impact on their mental health as an aggravating factor, especially for those belonging to one of the vulnerable groups of the population $(29,30)$.

The quality of life of seasonal workers is directly related to their financial situation, while their access to health care institutions is limited and a large percentage of workers do not have adequate insurance coverage $(31,32$, 33). These difficulties in combination with the financial difficulties that lead to the closure of companies due to the lockdown but also the health problems of the workers

\section{REFERENCES}

[1] Brooks S., Webster R., Smith L, Woodland L, Wessely S., Greenberg, N, Rubin, G. The psychological impact of quarantine and how to reduce it: rapid review of the evidence. The Lancet. 2020; 395: 912-920. DOI : $10.1016 / \mathrm{S} 0140-6736(20) 30460-8$

[2] WHO, 2020. COVID 19 Public Health Emergency of International Concern (PHEIC) Global Research and Innovation Forum: Towards a Research Roadmap. R\&D Blueprint: World Health Organization, pp. 1-7. Available: lead to the increase of stress and anxiety and has affected their quality of life negatively (34).

Previous studies linked the absence of psychological symptoms and the lower levels of stress in workers who were more psychological resilient. Durability directly related to a person's personality traits can reduce the onset of anxiety disorder and improve the quality of life of employees. Maintaining exercise and interpersonal relationships are some of the resilience enhancement techniques aimed at maintaining the mental health of workers who are the most affected by the spread of the pandemic and the quarantine measures (35).

\section{CONCLUSION}

The study has some limitations which need to be acknowledged. This is an online cross-sectional study and the relative contribution of the pandemic to the increase in mental health disorders needs to be evaluated using a longitudinal study design. There might have been the introduction of selection bias as those workers with limited internet access, older workers, participants with basic education ( $<6$ years) and those who might have been busy in their working duties might not have participated in the study. Moreover, there might be respondent bias as the findings were self-reported by workers and based on subjective scales of WHO-5 and GAD-7.

Despite limitations, this study provides early evidence on the mental health status among workers during the COVID-19 pandemic first lockdown in Greece, which should be of interest to policymakers, health facility managers and those involved in the response to COVID19 or any future epidemic study.

\section{ACKNOWLEDGMENTS}

None.

\section{AUTHORS' CONTRIBUTIONS}

The participation of each author corresponds to the criteria of authorship and contributorship emphasized in the Recommendations for the Conduct, Reporting, Editing, and Publication of Scholarly work in Medical Journals of the International Committee of Medical Journal Editors. Indeed, all the authors have actively participated in the redaction, the revision of the manuscript, and provided approval for this final revised version.

\section{COMPETING INTERESTS}

The authors declare no competing interests with this case.

\section{FUNDING SOURCES}

None.

https://www.who.int/publications/m/item/covid-19 public-health-emergency-of-international-concern(pheic)-global-research-and-innovation-forum

[3] Centers for Disease Control and Prevention Quarantine and isolation. [Accessed Nov 30, 2020].Available: https://www.cdc.gov/quarantine/index.html Date:2017 (

[4] Burhamah W, Alkhayyat A, Oroszlanyova, M, Alkenane A, Almansour, A, Behbehani $\mathrm{M}$ et al. The psychological burden of the COVID-19 pandemic and associated 
lockdown measures: Experience from 4000 participants. J Affect Diso. 2020; 277: 977-985.

DOI: $10.1016 /$ j.jad.2020.09.014

[5] Kamerāde D, Wang S, Burchell B, Balderson SU, Coutts, A. A shorter working week for everyone: how much paid work is needed for mental health and well-being? Soc Sci Med. 2019;112353.

DOI: 10.1016/j.socscimed.2019.06.006.

[6] Lai J, Ma S, Wang, Y, Cai Z, Hu J, Wei N, Tan H. Factors associated with mental health outcomes among health care workers exposed to coronavirus disease 2019. JAMA. 2020; 3: e203976.

DOI: $10.1001 /$ jamanetworkopen.2020.3976

[7] Bech P. Health-related quality of life measurements in the assessment of pain clinic results. Acta Anaesthesiol Scand. 1999; 43:893-896. DOI: $10.1034 / j .1399-6576.1999 .430906 . x$

[8] Spitzer RL, Kroenke K, Williams JBW, Lowe B. A brief measure for assessing generalized anxiety disorder. Arch Inern Med. 2006; 166:1092-1097. DOI: 10.1001/archinte.166.10.1092

[9] Torales J, O'Higgins M, Castaldelli-Maia JM, Ventriglio A. The outbreak of COVID-19 coronavirus and its impact on global mental health. Int J Soc Psychiatry. 2020; 0020764020915212.

DOI: $10.1177 / 0020764020915212$

[10] Chen Q, Liang M, Li, Y, Guo J, Fei D, Wang, L et al. Mental health care for medical staff in China during the COVID-19 outbreak. Lancet Psychiatry. 2020;7(4): 15-6. DOI: 10.1016/S2215-0366(20)30078-X

[11] Pfefferbaum, B, North CS. Mental health and the Covid19 pandemic. N Engl J Med. 2020; 383: 510-512. DOI: $10.1056 / \mathrm{NEJMp} 2008017$

[12] Zhou, X. Psychological crisis interventions in Sichuan Province during the 2019 novel coronavirus outbreak. Psychiatry Res. 2020; 286: 112895. DOI: $10.1016 /$ j.psychres.2020.112895

[13] Duan, L., Zhu, G. Psychological interventions for people affected by the COVID-19 epidemic. Lancet Psychiatry 2020; 7: 300-302.

DOI: $10.1016 / \mathrm{S} 2215-0366(20) 30073-0$

[14] Yang, L, Yin J, Wang, D, Rahman, A, Li X. Urgent need to develop evidence-based self-help interventions for mental health of healthcare workers in COVID-19 pandemic. Psychol Med. 2020; 1-2. DOI: $10.1017 / \mathrm{S} 0033291720001385$

[15] Ho CS, Chee C, Ho R. Mental health strategies to combat the psychological impact of coronavirus disease 2019 (COVID-19) beyond paranoia and panic. Ann Acad Med Singapore. 2020; 49: 1-6. Available: https://pubmed.ncbi.nlm.nih.gov/32200399/

[16] Luo M, Guo L, Yu M, Wang H. The psychological and mental impact of Coronavirus disease 2019 (COVID-19) on medical staff and general public-A systematic review and meta-analysis. Psychiatry Res. 2020; 291: 113190. DOI: $10.1016 /$ j.psychres.2020.113190

[17] Du J, Dong L, Wang T, Yuan C, Fu R., Zhang L, Bouey J. Psychological symptoms among frontline healthcare workers during COVID-19 outbreak in Wuhan. Gen Hosp Psychiatry. 2020; S0163-8343(20): 30045-300451. DOI: $10.1016 /$ j.genhosppsych.2020.03.011

[18] Kim, Y. Nurses' experiences of care for patients with Middle East respiratory syndrome-coronavirus in South Korea. Am J Infect Control. 2018; 46:781-787. DOI: $10.1016 /$ j.ajic.2018.01.012

[19] Khalid I, Khalid TJ, Qabajah MR, Barnard AG., Qushmaq IA. Healthcare workers emotions, perceived stressors and coping strategies during MERS-CoV outbreak. Clin Med Res. 2016;1303:1-22. DOI: $10.3121 / \mathrm{cmr} .2016 .1303$

[20] Sun N, Shi S, Jiao D , Jiao D, Song R, Ma L., A qualitative study on the psychological experience of caregivers of COVID-19 patients. Am J Infect Control. 2020; 48(6): 592-598.

DOI: 10.1016/j.ajic.2020.03.018

[21] Salazar de Pablo G, Vaquerizo-Serrano J, Catalan A, Arango C, Moreno C, Ferre F et al. Impact of coronavirus syndromes on physical and mental health of health care workers: systematic review and meta-analysis. J Affect Disord. 2020; 275: 48-57. DOI: $10.1016 /$ j.jad.2020.06.022

[22] O'Neill J W, Davis K. Work stress and well-being in the hotel industry. I J Hosp Man. 2011; 30 (2):385-390. DOI: $10.1016 / j . \mathrm{jijhm} .2010 .07 .007$

[23] Karatepe OS, Tizabi L Z. Work-related depression in the hotel industry: A study in the United Arab Emirates. I J Cont Hosp Man.2011; 23(5): 608-623. DOI: $10.1108 / 09596111111143368$

[24] Ross GF. Tourism industry employee work stress-A present and future crisis. J Trav Tour Man. 2005; 19 (2/3): 133-147. DOI: $10.1300 / J 073 v 19 n 02 \_11$

[25] Sönmez S, Apostolopoulos Y, Lemke MK, Hsieh YCJ. Understanding the effects of COVID-19 on the health and safety of immigrant hospitality workers in the United States. Tour Man Persp. 2020; 35: 100717. DOI: $10.1016 / j . t m p .2020 .100717$

[26] Kang HS, Son YD, Chae SM, Corte C. Working experiences of nurses during the Middle East respiratory syndrome outbreak. Int J Nurs Pract. 2018;24:e12664. DOI: $10.1111 /$ ijn. 12664

[27] Sagone E, De Caroli ME. A correlational study on dispositional resilience, psychological well-being, and coping strategies in university students. Am J Educ Res. 2014; 2 : 463-471. DOI: 10.12691/education-2-7-5

[28] Hjemdal O, Vogel PA, Solem S, Hagen K, Stiles TC. The relationship between resilience and levels of anxiety, depression, and obsessive-compulsive symptoms in adolescents. Clin Psychol Psychother. 2010; 18 :314-321.

DOI: $10.1002 / \mathrm{cpp} .719$

[29] Krause N. Disparities in prevalence, treatment, and control of hypertension among low wage immigrant workers beyond health insurance coverage: The Las Vegas Hotel room Cleaners Blood Pressure Study. J Hyper Mana. 2015; 1(1): 1-8. DOI: $10.23937 / 2474-3690 / 1510003$

[30] Rosemberg MS, Ghosh B, Shaver J, Militzer M, Seng J, McCullagh M. Blood pressure and job domains among hotel housekeepers. J H Disp Res Pract. 2018; 11(3): 101115 DOI: $10.1002 /$ ajim.22209

[31] Hsieh J, Sönmez S, Apostolopoulos Y, Lemke M. Perceived workplace mistreatment by latina hotel housekeepers. J Prev Ass Reh. 2017; 56(1): 55-65. DOI: $10.3233 /$ WOR-162467

[32] Hsieh Y, Apostolopoulos Y, Sönmez S. World at work: Hotel cleaners. Occu Envi Med. 2013; 70(5): 360-364. DOI: 10.1136/oemed-2012-100986

[33] Hsieh Y, Apostolopoulos Y, Hatzudis K, Sönmez S. Occupational exposures and health outcomes among hispanic hotel cleaners. Hisp H Care Inter. 2014; 12(1): 615. DOI: $\underline{10.1891 / 1540-4153.12 .1 .6}$

[34] Feaster M, Arah OA, Krause N. Effort-reward imbalance and ambulatory blood pressure among female Las Vegas hotel room cleaners. Am J Ind Med. 2019; 62(6): 523534. DOI: $10.1002 /$ ajim. 22980

[35] Killgore WDS, Taylor EC, Cloonan SA, Dailey NS. Psychological resilience during the COVID-19 lockdown. Psychiatry Res. 2020; 291: 113216.

DOI: $\underline{10.1016 / \text { j.psychres.2020.113216 }}$ 